\title{
Regional climate change projections for the Tully sugar region
}

\author{
J. Sexton ${ }^{\mathrm{a}, \mathrm{b}}, \underline{\text { Y. Everingham }}^{\mathrm{a}, \mathrm{b}}$ and D. Skocaj ${ }^{\mathrm{a}, \mathrm{c}}$ \\ ${ }^{a}$ School of Engineering and Physical Sciences, James Cook University ${ }^{b}$ Tropical Environmental \\ Sustainability Science ${ }^{c}$ BSES Limited, Tully \\ Email: yvette.everingham@jcu.edu.au
}

\begin{abstract}
Faced with the challenges of a changing climate, it is imperative that primary industry decision makers have access to climate projections on a local scale. In the Australian sugar industry, changes in maximum and minimum temperature, radiation and rainfall can significantly affect future economic and environmental sustainability. In northern regions an increase in rainfall during the harvest season can lead to crop standover and lower economic returns. Modelling the effects of climate change at a local scale will help develop regional management strategies.
\end{abstract}

General Circulation Models (GCMs) allow researchers to explore projections of climate variables under a range of possible future emission scenarios. However, current outputs from GCMs are often only available at a coarse resolution (up to $300 \mathrm{~km}$ by $300 \mathrm{~km}$ ). As a result many small scale conditions that can affect climate variables are often not represented in GCM outputs. Sugarcane in Australia is primarily grown in a narrow band on the eastern coast. The Tully region of northern Queensland is situated between the World Heritage Listed Wet Tropics Rainforest and Great Barrier Reef. Topographical changes across the Tully sugarcanegrowing region result in climatology varying spatially. Downscaled GCMs can provide a bridge between large scale climate projections and the need for local climate variables. This paper explores climate change projections for maximum and minimum temperature, radiation and rainfall in the Tully sugarcane-growing region at a high spatial resolution.

Temperature and rainfall data were obtained from 11 GCMs for the period 1961 to 2000. Projections for this period were based on $20^{\text {th }}$ century forcings $(20 \mathrm{C} 3 \mathrm{M})$ as described by the International Panel of Climate Change (IPCC). GCM projections for the period 2046 to 2065 were also obtained, based on a high emissions scenario (A2). A statistical downscaling methodology was used to downscale daily temperature and rainfall data on a 0.05 by 0.05 decimal degree grid (approximately $5 \mathrm{~km}$ by $5 \mathrm{~km}$ ). Data were downscaled for grid locations known to grow sugarcane within the Tully region. Daily radiation data were not available using the downscaling process. Instead, daily radiation data were generated from downscaled rainfall and temperature data. Equations for daily radiation were parameterised using temperature and rainfall data from a nearby high quality weather station and calculated total solar flux. Estimates were bias corrected to replicate weather station records of radiation.

The projected change in each of the four climate variables was assessed on a regional level for the $11 \mathrm{GCMs}$ and spatial variations within the region were identified. For temperature and radiation variables, the absolute projected change was calculated. For rainfall the projected relative change was calculated. The relative change was defined as the percent change from the baseline period (1961 to 2000). Projected changes were analysed at each grid point for summer, autumn, winter and spring. The regional mean change was calculated for each GCM and a $95 \%$ bootstrapped confidence interval was produced for the $25^{\text {th }}, 50^{\text {th }}$ and $75^{\text {th }}$ percentiles of the paired differences. The percentiles of projected change across the range of GCMs were used to capture the uncertainty between model projections. If the $95 \%$ confidence interval of the $50^{\text {th }}$ and $75^{\text {th }}$ $\left(25^{\text {th }}\right)$ percentile captured only positive (negative) values, an increase (decrease) was considered plausible. An increase (decrease) was considered highly plausible if the confidence intervals for the $25^{\text {th }} 50^{\text {th }}$ and $75^{\text {th }}$ all captured positive (negative) values.

For the Tully region, an increase in temperature was considered highly plausible for all seasons under A2 simulated forcings. A projected decrease in radiation was considered highly plausible for winter and spring and plausible for autumn. A relative increase in radiation was plausible for summer and a relative increase in rainfall was considered plausible for spring. However, projected changes in seasonal rainfall varied spatially within the Tully region. An increase in seasonal temperature and rainfall may require changes to traditional management strategies. High resolution climate change projections can help industry decision makers develop localised, robust adaptation strategies. Local adaptations are vital for an economically and environmentally sustainable future.

Keywords: Temperature, radiation, rainfall, GCM, downscale 


\section{INTRODUCTION}

Agricultural industries are highly dependent on climatology for production. Faced with a changing climate it is more important than ever that decision makers within industry have a comprehensive understanding of climatology on a local scale. The modelling community is vital to providing the information necessary for industry to make robust adaptation strategies. In the Australian sugar industry, changes in maximum and minimum temperature, radiation and rainfall can all significantly affect the future economic and environmental sustainability.

The Australian sugar industry is located primarily along the eastern coastline, between mountain ranges to the west and the Pacific Ocean to the east (Figure 1). How climate variables affect the sugar industry can differ between and within regions. Warmer conditions could increase production losses due to higher pest and disease pressure (Park et al., 2010). In northern cane-growing regions excessive rainfall during summer can impede crop growth (Everingham et al., 2003) whereas large rainfall events during the harvest season (winter and spring) can reduce profitability due to crop standover and lower sugar content (Antony et al., 2002). However, models have projected increased cane yields due to higher atmospheric carbon dioxide $\left(\mathrm{CO}_{2}\right)$ concentrations (Marin et al., 2013). Robust management strategies will be required to balance the potential risks and opportunities of a changing climate.

Projections from General Circulation Models (GCMs) are available for a range of simulated emission scenarios. These data are available in archives such as the Coupled Model

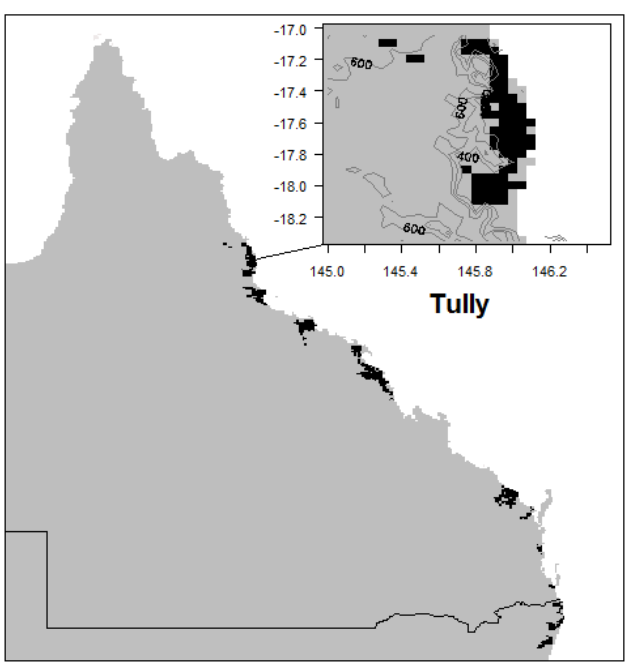

Figure 1. Sugar growing regions in Australia. The Tully region in the north is located between high mountain ranges and the coast.

Intercomparison Project (CMIP3) database. The "2007 Climate Change in Australia" technical report documented the $10^{\text {th }}$ and $90^{\text {th }}$ percentiles for rainfall projections from 25 GCMs (Pearce et al., 2007). Pearce et al. (2007) considered low, medium and high emissions for 2030, 2050 and 2070. Under a high emissions scenario the report suggested an increase in maximum and minimum temperatures, but no likely change in radiation or rainfall across Queensland, where 'likely' was defined as agreement among at least two thirds of the models. Data from GCMs are currently produced at low spatial resolutions (up to 300 by $300 \mathrm{~km}$ ). In heterogeneous terrain GCMs can fail to capture local climate patterns. By downscaling GCM projections of climate variables it is possible to produce projections at a higher spatial resolution.

Downscaling techniques can be classified as dynamical or statistical (Fowler et al., 2007). Dynamical downscaling techniques model the physical processes of climate variables. Statistical downscaling techniques develop mathematical equations that relate large-scale atmospheric variables to local climate variables. Downscaling techniques have previously been used in Australia to model runoff (Teng et al., 2012) and productivity in wheat (Liu et al., 2011).

In order to develop local adaptation strategies, models of climate variables are needed at a high spatial resolution. The objective of this paper is to investigate downscaled climate change projections for maximum and minimum temperature, radiation and rainfall in the Tully sugarcane-growing region.

\section{GENERATING HIGH RESOLUTION CLIMATE DATA}

Daily rainfall and temperature data from 11 GCMs (Table 1) were extracted from the CMIP3 database (Meehl et al., 2007). The 11 GCMs were chosen for the availability of daily data in the required region, for current and future projections (Timbal et al., 2009). GCMs were parameterized for $20^{\text {th }}$ century emissions (20C3M) for the period 1961:2000 (20C3M) to represent a climatic baseline (PCMDI, 2002). Projections for the period 2046 to 2065 were produced under the "A2" scenario, representing a future with high population growth, high energy use and high greenhouse gas emissions (Nakicenovic and Swart, 2000).

The analogues statistical downscaling method of Timbal et al. (2009) was used to model rainfall and temperature data for the Tully sugarcane-growing region. The statistical downscaling method developed a series of mathematical equations to relate observed daily synoptic patterns to observed daily rainfall, maximum temperature and minimum temperature. The downscaling methodology used rainfall and temperature data from the Australian Water Availability Project (AWAP) on a 0.05 by 0.05 decimal degree 
Sexton et al., Regional climate change projections for the Tully sugar region

Table 1. General Circulation Models used in analysis

grid, as baseline climatology. The Bureau of Meteorology (BoM) provided downscaled rainfall and temperature data for each GCM under the $20 \mathrm{C} 3 \mathrm{M}$ and $\mathrm{A} 2$ scenarios, on a 0.05 by 0.05 decimal degree grid.

Government land use data and advice from industry experts was used to identify the Tully sugarcane-growing region. In total 77 "pixels" of 0.05 by 0.05 decimal degrees were identified

\begin{tabular}{|l|l|l|}
\hline ID number & ID Code & \multicolumn{1}{|c|}{ Institute } \\
\hline GCM1 & CCM & Canadian Climate Centre \\
GCM2 & CNRM & Metro-France \\
GCM3 & CSIRO & Commonwealth Scientific and Industrial Research Organisation \\
GCM4 & CSIRO2 & Commonwealth Scientific and Industrial Research Organisation \\
GCM5 & GFDL1 & Geophysical Fluid Dynamics Lab \\
GCM6 & GFDL2 & Geophysical Fluid Dynamics Lab \\
GCM7 & GISSR & NASA/Goddard Institute for Space Studies \\
GCM8 & IPSL & Institute Pierre Simon Laplace \\
GCM9 & MIROC & Centre for Climate Research \\
GCM10 & MPI & Max Planck Institute for Meteorology DKRZ \\
GCM11 & MRI & Meteorological Research Institute \\
\hline
\end{tabular}

(Figure 1). Daily radiation data were not available using the downscaling process. Instead, daily radiation data were calculated from downscaled temperature and rainfall data for each GCM using the methodology of Liu and Scott, (2001). Daily radiation of day (j), (Q(j)) was calculated by modifying total daily solar flux $\left(Q_{0}(j)\right)$ using rainfall for three consecutive days $(R(j), R(j-1), R(j+1)$ and the diurnal range of air temperature. Estimates of daily radiation were bias corrected to maximise the fit to radiation records from a nearby BoM station.

\section{METHODOLOGY}

\subsection{Model validation}

The temporal mean $\bar{Y}($ season,GCM,scenario,pixel $)$ for maximum $(\overline{\operatorname{Tmax}})$ and $\operatorname{minimum}(\overline{\operatorname{Tmin}})$ temperature, radiation $(\overline{\mathrm{Rad}})$ and rainfall $(\overline{\mathrm{Rain}})$ were calculated for each season $=\{$ summer, autumn, winter, spring $\}$, pixel $=\{1, \ldots, 77\}$ and $G C M=\{$ GCM1, GCM2,.., GCM11 $\}$ for 20C3M and A2 scenarios. The spatio-temporal mean $\bar{Y}$ (season, GCM,scenario) was defined as the mean of temporal means across all pixels. Bias was calculated between AWAP spatio-temporal mean radiation, temperature and rainfall and the spatio-temporal means for downscaled GCMs. Radiation from AWAP data were calculated using the same technique as GCMs using AWAP rainfall and temperature data. Spatial patterns of downscaled GCMs and AWAP data seasonal data were also compared.

\subsection{Comparing future and historic climate projections}

The paired differences in modelled projections were computed between the A2 (2046 to 2065) and 20C3M (1961 to 2000) scenarios. For temperature and radiation, the average temporal mean of paired differences for each season and pixel were plotted spatially. For example, the average temporal mean of paired GCM differences in maximum temperature were calculated as,

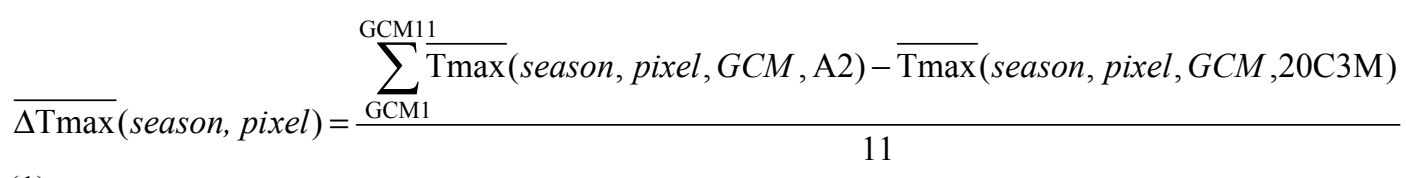

For rainfall the relative change in the temporal means were calculated as a percentage change from $20^{\text {th }}$ century conditions

$\overline{\Delta \text { Rain }}($ season, pixel $)=\frac{\sum_{\mathrm{GCM} 11}^{\mathrm{GCM} 11}\left[\frac{\overline{\text { Rain }}(\text { season, pixel, GCM,A2) }-\overline{\text { Rain }}(\text { season, pixel, GCM }, 20 \mathrm{C} 3 \mathrm{M})}{\overline{\operatorname{Rain}}(\text { season, pixel, GCM }, 20 \mathrm{C} 3 \mathrm{M})}\right] \times 100}{11}$

The change in regional spatio-temporal means for each GCM, were calculated similarly. For example the regional change in spatio-temporal mean rainfall was calculated as, 


$$
\overline{\Delta \operatorname{Rain}}(\text { season, } G C M)=\frac{\sum_{\text {Pixel1 }}^{\text {Pixel777 }}\left[\frac{\overline{\text { Rain }}(\text { season, pixel, GCM, A2) }-\overline{\text { Rain }}(\text { season, pixel, GCM }, 20 \mathrm{C} 3 \mathrm{M})}{\overline{\text { Rain }}(\text { season, pixel, GCM,20C3M })}\right] \times 100}{77}
$$

Downscaled GCMs that produce large positive values in (3) indicate a relative increase (positive change) in rainfall under $\mathrm{A} 2$ forcings, when compared to $20^{\text {th }}$ century forcings $(20 \mathrm{C} 3 \mathrm{M})$. Downscaled GCMs that produce large negative values indicate a relative decrease (negative change).

Equation (3) represents an independent sample of eleven spatio-temporal mean paired differences in seasonal rainfall. Here it is assumed that the eleven downscaled GCMs are representative of a larger parent population of climate models. The assumption of an independent sample was considered reasonable as the models selected were from a range of the 'families' of GCMs identified by Mason and Knutti (2011). Bootstrapped samples (Good, 1997) were used to produce $95 \%$ confidence intervals for the $25^{\text {th }}, 50^{\text {th }}$ and $75^{\text {th }}$ percentiles of the distribution of paired model differences (Everingham et al., 2013). For example, (3) was used to produce

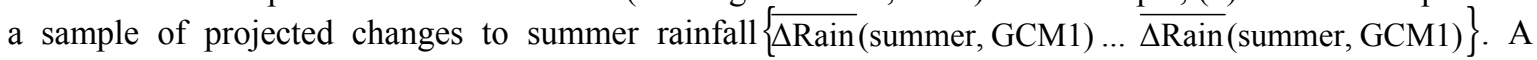
random re-sample was produced with replacement and the $50^{\text {th }}$ percentile was recorded. The process was repeated to obtain 1000 sample $50^{\text {th }}$ percentiles. A $95 \%$ confidence interval was defined from the bootstrapped samples. Similarly confidence intervals were produced for temperature and radiation data.

An increase was considered 'plausible' when the confidence interval for the $50^{\text {th }}$ percentile captured only positive values and 'highly plausible' if the confidence interval for the $25^{\text {th }}$ percentile captured only positive values. Decreasing rainfall was considered 'plausible' ('highly plausible') when the confidence interval for the $50^{\text {th }}\left(75^{\text {th }}\right)$ percentile captured only negative values (Everingham et al., 2013). Our definition of plausible and highly plausible is independent of the magnitude of the change. However the reader can examine the width of the confidence intervals to gauge the variability of the $25^{\text {th }}, 50^{\text {th }}$ and $75^{\text {th }}$ percentiles of the paired differences._The authors recognise that definitions for 'plausible' or 'likely' changes differ within the literature.

\section{RESULTS}

\subsection{Model Validation}

Downscaled GCMs underestimated maximum temperature in autumn and overestimated seasonal minimum temperatures. Average daily radiation were underestimated in autumn and winter but were well represented in summer and autumn. Total seasonal rainfall was generally underestimated in summer and overestimated in autumn.

An average across GCMs reproduced spatial patterns of AWAP temperature and radiation data well. A slight north/south difference in bias was evident but not consistent across seasons. A slight decrease in bias magnitude was evident in autumn, winter and spring for radiation data. Rainfall data were the most spatially variable. GCMs managed to reproduce this variability well especially in capturing a small area of high rainfall at approximately $-17.4^{\circ}$ latitude. Patterns of bias were least consistent for rainfall especially in autumn and spring where southern parts of the region were underestimated while northern regions were overestimated.

\subsection{Comparing future and historic climate projections}

On a regional scale all GCMs agreed on the direction of change in minimum and maximum temperature under A2 forcings. Projected increases were largest in autumn (maximum) and winter (minimum). For individual GCMs, the projected change under the A2 scenario ranged from 0.5 to 1.5 (degrees C) for maximum temperature. Changes were slightly higher for minimum temperature ranging from 0.6 to 2.3 degrees. Based on bootstrapped 95\% confidence intervals, an increase in maximum and minimum temperatures were considered highly plausible for all seasons (Figure 2).

Radiation projections based on downscaled GCMs simulated changes in ranging from -1.7 to $0.9 \mathrm{Mj} / \mathrm{m}^{2}$ across all seasons with projected decreases greatest in winter. A projected increase in radiation was considered plausible for summer. A decrease was considered plausible in autumn and highly plausible in winter and spring. 
Projections of the relative change in seasonal rainfall had the lowest levels of model agreement. Relative change in projected rainfall ranged from $-24.6 \%$ (winter) to $64.6 \%$ (spring) across seasons. A relative increase in spring rainfall was considered plausible under a high emissions scenario.

Within the Tully region there was little spatial variation in the projected change in radiation and temperature under the A2 scenario (Figure 3). Minimum temperature increases were slightly higher in northern districts for winter and spring. Slight differences in northern and southern districts were also evident for radiation projections in summer and spring. The projected relative change in rainfall for Tully was more spatially variable. In autumn and winter the northern and southern districts of the region projected a small increase $(5 \%)$, while the centre of the region projected a small decrease $(-5 \%)$.

\section{DISCUSSION}

Direct outputs from general circulation models may not truly represent local variability in climate change projections. This is especially true for highly heterogeneous regions such as the Australian sugar industry. In order for industry to make effective adaptation strategies, there is a need to supply projections on a local scale. Use of a downscaling technique can provide projections of climate variables at a high spatial resolution. High resolution projections allow researchers to investigate how climate change may vary between districts within a region.

Projected increases in maximum and minimum temperature $\left(1^{\circ} \mathrm{C}\right.$ to $\left.2^{\circ} \mathrm{C}\right)$ are similar to the results of earlier studies including Pearce et al. (2007). Higher minimum temperatures in autumn and winter may translate to a longer growing season. However, crop damage due to diseases may be greater as temperatures increase as many important sugarcane diseases favour warm, moist conditions (Chakraborty et al., 1998). An increase in radiation during summer may translate to higher cane yields. However this may be offset by the projected decrease in radiation during winter and spring. Reduced radiation during winter and spring may restrict crop growth, especially early harvested ratoons and plant cane crops.

An increase in rainfall during the harvest season would cause greater disruptions to harvesting operations, increasing the risk of standover. There may also be significant damage to the cane stool and row profile where attempts are made to maximise the harvest, compromising ratoonability and field drainage (Kingston 2011).

As winter is normally associated with cool, wet conditions, most of the sugarcane in the Tully region is planted during spring. Increased spring rainfall may adversely affect germination and crop establishment, shorten the planting window or in extreme cases sugarcane may need to be replanted. Additional changes to the farming system may be required, such as raised
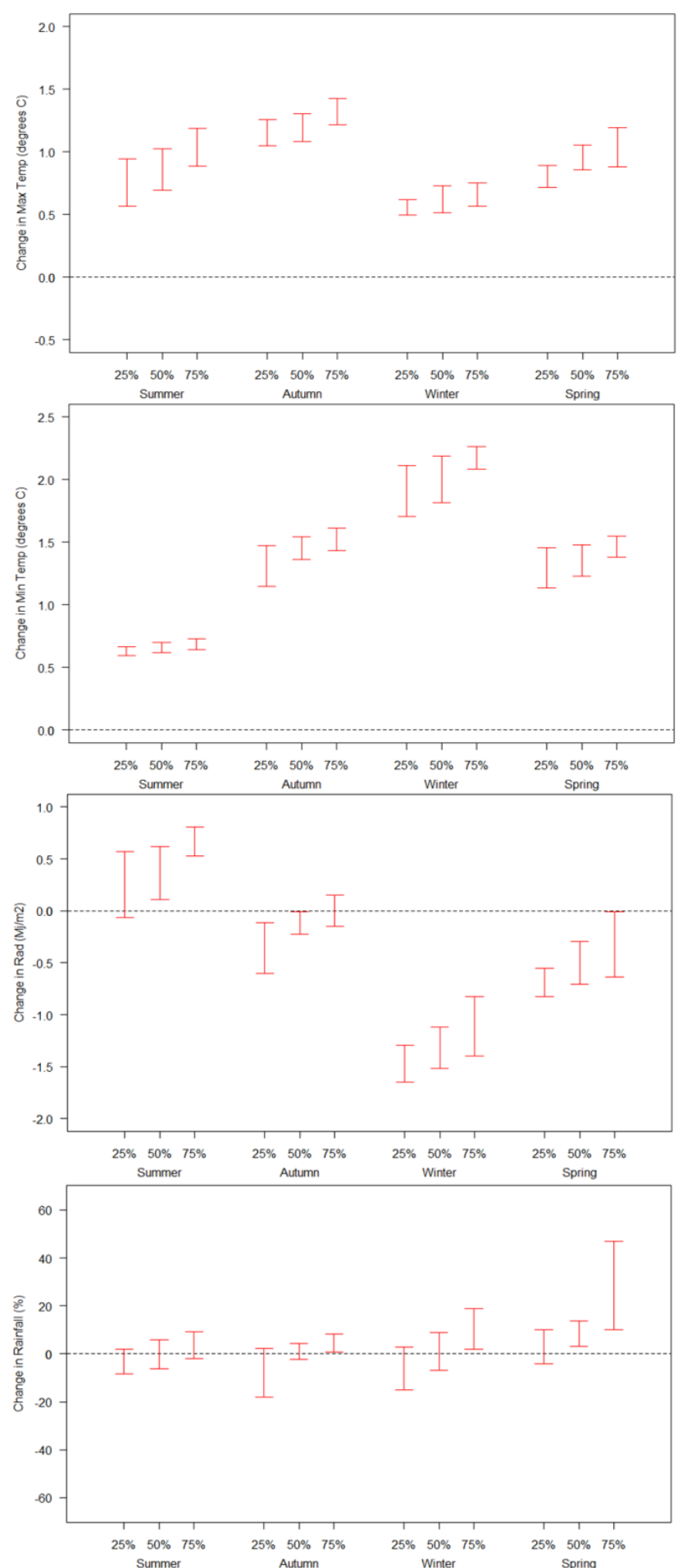

Figure 2. Bootstrapped 95\% confidence intervals for the $25^{\text {th }}, 50^{\text {th }}$ and $75^{\text {th }}$ percentiles of regional spatio-temporal mean differences for (a) maximum temperature, (b) minimum temperature, $(\mathrm{c})$ radiation and $(\mathrm{d})$ rainfall. Positive values represent a projected increase while negative values represent a projected decrease. 
beds, mound planting and better in-field drainage, to reduce the impact of waterlogging on crop growth resulting from increased spring rainfall.

Projected increases in temperature and radiation were relatively uniform across the Tully region. Spatial variability was highest in rainfall projections. Decreases were primarily located in the centre of the Tully mill area while the northern (e.g. Silkwood) and southern (e.g. Murray) districts increased. Although a change was not considered plausible for summer or autumn rainfall on a regional level by our definition (section 3.2), projected differences in district rainfall suggest that targeted adaptation strategies could be developed. For example, districts where rainfall is projected to increase could be harvested before districts with a lower risk of increased rainfall.

\section{CONCLUSION}

General circulation models allow researchers to identify possible trends in climate variables important to agricultural industries. GCM outputs are produced on a large scale and cannot capture local variability. By using a downscaling technique, spatial variability in projected changes can be assessed within a single region. In this paper we have presented projected changes in maximum and minimum temperature, radiation and rainfall under a high (A2) emissions scenario for the Tully sugarcane-growing region. Uncertainty between models is a major concern in both climate change analysis (Power et al., 2011) and crop simulations (Rotter et al., 2011). By producing confidence intervals on percentiles of model projections, this research aimed to identify the level of uncertainty in climate change projections. It is important to recognise that the GCM projections capture only a subset of future uncertainty. Consequently, measures of future variability such as confidence intervals are conservative.

On a regional scale, increases in maximum and minimum temperature were considered highly plausible for all seasons and an increase in rainfall was considered plausible during spring. Disease (and pest) management will continue to be a priority under these future climatic conditions. Spatial variability in projections of temperature and rainfall suggest that different management adaptations may be required
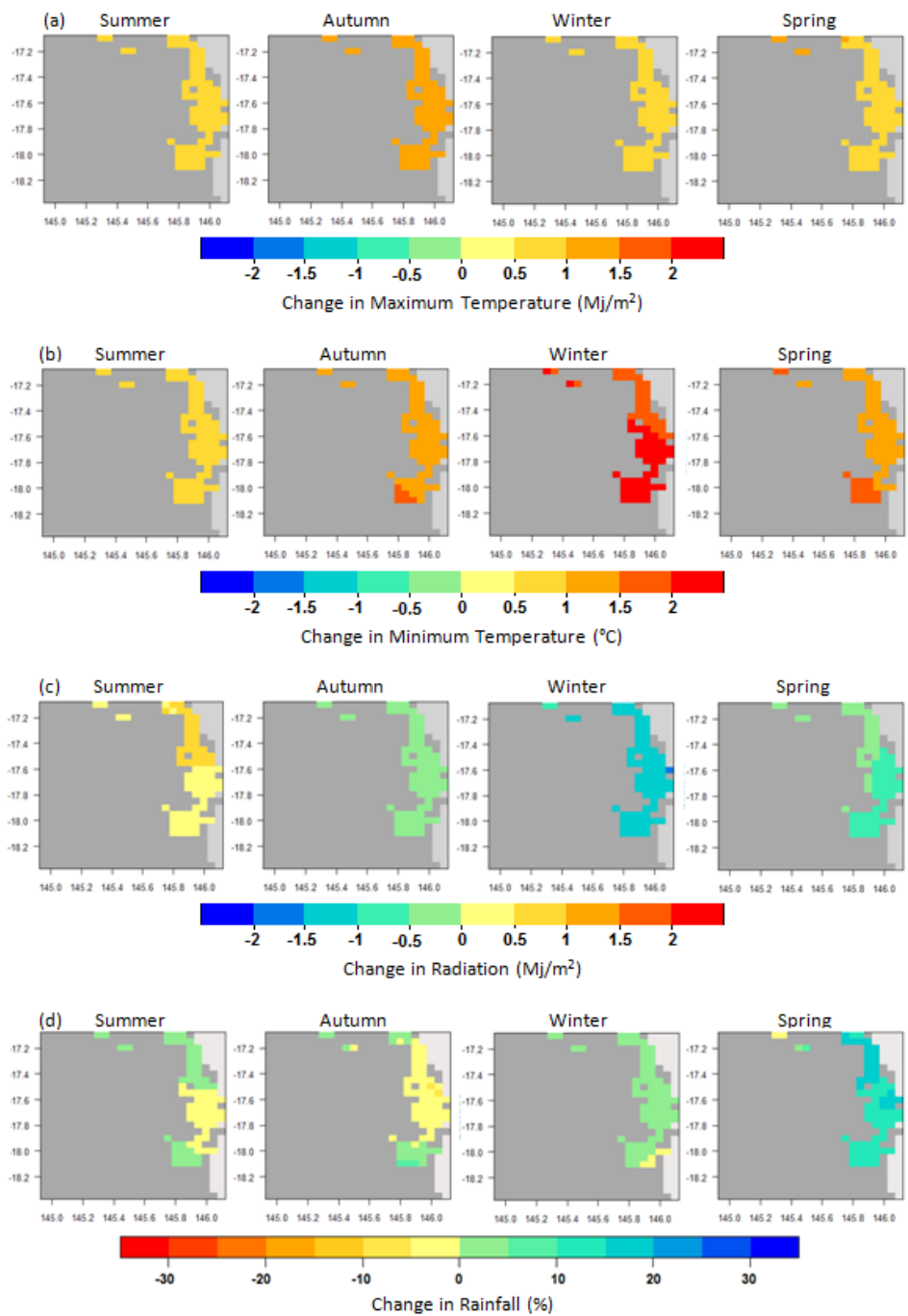

Figure 3. Spatial patterns in average change across 11

GCMs for: (a) maximum temperature, (b) minimum temperature, (c) radiation and (d) rainfall. Rainfall is presented as a percent change relative to the baseline period 1961:2000. Positive values represent a projected increase while negative values represent a projected decrease.

in different districts. For example harvesting and planting operations could be modified to reduce the impact of wet weather and to take advantage of earlier planting opportunities.

Downscaled climate projections could extend crop model research from the regional level down to the district level. This would help develop adaptation strategies for an economically and environmentally sustainable future. However, collaboration between researchers and industry decision makers will remain the most vital step in developing viable adaptation strategies. 
Sexton et al., Regional climate change projections for the Tully sugar region

\section{ACKNOWLEDGEMENTS}

The Authors would like to thank Yang Wang and Alex Evans for their help with data acquisition. Rodney Neilson, John Markley, Paul Brown, Ben Mayo and Dale Thomas for help with identification of sugargrowing regions. Bertrand Timbal (BoM) for supplying downscaled daily GCM projections for rainfall and temperature. We acknowledge the international modelling groups for providing their data for analysis, the Program for Climate Model Diagnosis and Intercomparison (PCMDI) for collecting and archiving the model data, the JSC/CLIVAR Working Group on Coupled Modelling (WGCM) and their Coupled Model Intercomparison Project (CMIP) and Climate Simulation Panel for organizing the model data analysis activity, and the IPCC WG1 TSU for technical support. The IPCC Data Archive at Lawrence Livermore National Laboratory is supported by the Office of Science, U.S. Department of Energy. This research was funded by the Sugar Research and Development Corporation (JCU032).

\section{REFERENCES}

Antony, G., Everingham, Y. and Smith, M. (2002). Financial benefits of using climate forecasting: a case study. Proceedings of the Conference of the Australian Society of Sugar Cane Technologists, 24, 153-159.

Chakraborty, S., Murray, G., Magarey, P., Yonow, T., O’Brien, R., Croft, B., Barbetti, M., Sivasithamparam, K., Old, K., Dudzinski, M., Sutherst, R., Penrose, L., Archer, C. and Emmett, R. (1998). Potential impact of climate change on plant disease of economic significance to Australia. Australasian Plant Pathology, 27(1), 15-35.

Everingham, Y.L., Muchow, R.C., Stone, R.C. and Coomans, D.H. (2003). Enhancing sugarcane yield forecasting capability using SOI phases: A case study for north eastern Australia. International Journal of Climatology, 23, 1211-1218.

Everingham, Y., Sexton, J. and Timbal, B. (2013). Downscaled rainfall projections for the Burdekin, Mackay and NSW. Proceedings of the Australian Society of Sugar Cane Technologists, 31, 144-152.

Fowler, H.J., Blenkinsop, S. and Tebaldi, C. (2007). Linking climate change modelling to impacts studies: recent advances in downscaling techniques for hydrological modelling. International Journal of Climatology, 27, $1547-1578$.

Good, P.I. (1997). Permutation Tests: a Practical Guide to Resampling Methods for Testing Hypotheses SpringerVerlag, New York.

Kingston, G. (2011). The difficult 2010 sugarcane harvest in Australia: causes, effects and learnings. Proceedings of the South African Sugar Technologists' Association, 84, 28-36.

Liu, D.L. and Scott, B.J. (2001). Estimation of solar radiation in Australia from rainfall and temperature observations. Agricultural and Forest Meteorology, 106, 41-59.

Liu, D.L., Timbal, B., Mo, J. and Fairweather, H. (2011). A GIS-based climate change adaptation strategy tool. International Journal of Climate Change Strategies and Management, 3, 140 - 155.

Marin, F.R., Jones, J.W., Singels, A., Royce, F., Assad, E.D., Pellegrino, G.Q. and Justino, F. (2013). Climate change impacts on sugarcane attainable yield in southern Brazil. Climatic Change, 117, 227-239.

Masson, D. and Knutti, R. (2011). Climate model genealogy. Geophysical Research Letters, 38(8), L08703.

Meehl, G.A., Covey, C., Delworth, T., Latif, M., McAvaney, B., Mitchell, J.F.B., Stouffer, R.J. and Taylor, K.E. (2007). The WCRP CMIP3 multi-model dataset: A new era in climate change research. Bulletin of the American Meteorological Society, 88, 1383-1394.

Nakicenovic, N. and Swart, R. (2000). Special report on emissions scenarios: A special report of Working Group III of the International Panel on Climate Change. Cambridge University Press, Cambridge.

Park, S., Crimp, S., Inman-Bamber, G. and Everingham, Y.L. (2010). Sugar, in: Howden, M.and Stokes, C. (Eds.), Adapting Agriculture to Climate Change: Preparing Australian Agriculture, Forestry and Fisheries. CSIRO Publishing.

PCMDI (2002). 20th Century climate in coupled models: A CMIP pilot project. available at: http://wwwpcmdi.llnl.gov/projects/cmip/ann_20c3m.php (accessed 31 January 2013).

Pearce, K.B., Holper, P.N., Hopkins, M., Bouma, W.J., Whetton, P., Hennessy, K.J. and Power, S. (2007). Climate change in Australia: Technical Report 2007, CSIRO/Bureau of Meteorology technical report. CSIRO Marine and Atmospheric Research, Aspendale.

Power, S., Delage, F., Colman, R., Moise, A. (2011). Consensus on twenty-first-century rainfall projections in climate models more wide spread than previously thought. Journal of Climate, 25(11), 3792-3809.

Rotter, R.P., Carter, T.R., Olesen, J.E. and Porter, J.R. (2011). Crop-climate models need an overhaul. Nature Climate Change, 1(4), 175-177.

Teng, J., Chiew, F.H.S., Timbal, B., Wang, Y., Vaze, J. and Wang, B. (2012). Assessment of an analogue downscaling method for modelling climate change impacts on runoff. Journal of Hydrology, 472-473, 111-125.

Timbal, B., Fernandez, E. and Li, Z. (2009). Generalization of a statistical downscaling model to provide local climate change projections for Australia. Environmental Modelling and Software, 24, 341-358. 